\title{
COPYLEFT LICENCE I RAZVOJ PRAVA INTELEKTUALNE SVOJINE
}

\author{
Ivan Nikčević1, \\ Ana Radović ${ }^{2}$ \\ 1 Univerzitet Singidunum, \\ Danijelova 32, \\ Beograd, Srbija \\ 2Dom kulture „Studentski grad”, \\ Bulevar Zorana Đinđića 179, \\ Beograd, Srbija
}

\begin{abstract}
Rezime:
Nastanak interneta je u velikoj meri promenio način iskorišćavanja autorskih dela. Imajući u vidu da je veliki broj dela široko dostupan i rasprostranjen na internetu, pojam autorskog prava se sve više dovodi u pitanje, i sve je veći broj dela koja su zaštićena copyleft licencama. U osnovi copylefta nalazi se pravo na slobodan pristup znanju, odnosno pravo da svako može određeno delo slobodno da koristi, preuredi i deli. Pojam copylefta relativno je noviji pojam koji zahteva podrobniju analizu, posebno uzimajući u obzir činjenicu da je sa njime upoznat mali broj ljudi na našem području. Osnovni cilj našeg istraživanja jeste upoznavanje sa pojmom copylefta, copyleft pokretom i copyleft licencom, ali i sa uticajem digitalnog okruženja na njihov razvoj.
\end{abstract}

Ključne reči:

internet, autorsko delo, copyleft, licenca, pokret.

\section{UVOD}

Osnovni predmet rada jeste sagledavanje razvoja kopileft (copyleft) pokreta, posebno imajući u vidu izazove digitalnog okruženja. U kojoj meri su se kopileft pokreti prilagodili digitalnom okruženju? Da li razvoj kopilefta prati razvoj digitalne tehnologije? Kako je digitalno okruženje uticalo na softver otvorenog koda? Da li se budućnost korišćenja autorskih dela na internetu nalazi u kopileftu? U kojoj meri je tradicionalni koncept autorskog prava (copyright) izgubio bitku pred izazovima digitale tehnologije? Ovo su samo neka od pitanja na koja ćemo nastojati da pronađemo odgovor u radu.

Osnovna hipoteza koju ćemo nastojati da dokažemo u radu glasi: Kopileft licence igraju važnu ulogu u razvoju prava intelektualne svojine, kao i u zaštiti prava zajednice da koristi intelektualnu svojinu u cilju razvoja

Correspondence:

Ivan Nikčević

e-mail:

inikcevic@singidunum.ac.rs i dobrobiti društva u skladu sa izazovima digitalnog okruženja. Razvoj kopilefta i kopileft licenci ide u korak sa razvojem digitalnog okruženja, pre svega interneta. S obzirom na to da je masovnost i dostupnost tuđeg rada jedna od prednosti digitalnih tehnologija, možemo zaključiti da razvoju kopileft licenci odgovara postojeće digitalno okruženje. 


\section{NASTANAK I RAZVOJ COPYLEFTA}

Začetnik ideje kopilefta jeste Ričard Stalman (Richard Stallman) koji je osmislio koncept Opštu javnu licencu - GNU GPL (GNU General Public License - GPL), kojom je postavio okvire pravne zaštite slobodnog softvera. Tvorac softvera koji želi da svoje delo učini slobodnim ne odriče se zakonom priznatih autorskih prava, već ga koristi tako što svoja ovlašćenja ustupa drugom licu.

Pravo na znanje jedno je od osnovnih ljudskih prava koje je garantovano i Univerzalnom deklaracijom o ljudskim pravima (The Universal Declaration of Human Rights 1948). „Pojam prava, a posebno liberalan koncept ljudskih prava leži u osnovi konstrukcije pristupa izvornom kodu kao osnovno ljudsko pravo... Stalman koristi jak koncept prava izvučen iz američkog ustava da opravda ovaj položaj: Ideja neotuđivih prava oličena u GNU GPL dolazi od očeva osnivača SAD” [1].

Moderne tehnologije su u velikoj meri uticale i promenile živote ljudi. Današnji svet je neprepoznatljiv u poređenju sa svetom od pre trideset godina, upravo zahvaljujući ekspanzivnom razvoju savremenih tehnologija. Svet je danas mnogo više povezan predstavljajući globalno selo u kome se komunikacija mnogo lakše i brže odvija. Znanje i pristup informacijama u velikoj meri su olakšani. Savremene tehnologije izvršile su veliki uticaj na kulturni sektor tako što su sada informacije dostupne svima i u svako doba. Tekstualni dokumenti, muzičke numere, slike, video zapisi i ostali oblici digitalnih kulturnih dobara dostpuni su svima posredstvom internet mreže. Književna dela poput knjiga i časopisa transformišu se u kiber prostoru jer mikroprocesor i internet dozvoljavaju korisnicima da slobodno umnožavaju, menjaju i dele radove koji se nalaze u elektronskim medijima.

Stvaraoci mnogih dela su se od davnina služili korišćenjem postojećeg materijala u stvaranju novog. Ovo ukazuje da je „kulturna baština važan resurs za razvoj kreativnosti u informacijskom društvu" [2]. Zato je od velikog značaja slobodan pristup različitim kulturnim dobrima poput knjiga, slika, muzičkih numera i softvera u smislu nastanka i izgradnje novih dela i u ovome je uloga i značaj kopilefta ogroman.

Iako je početak razvoja interneta obeležen slobodnom razmenom informacija, vremenom je ta sloboda suočena sa brojnim izazovima zbog „sve prisutnijih struktura kontrole vlasništva nad elementima digitalnih dobara" [2]. Vlasnici autorskog prava vrlo često nisu pojedinci, nego velike kompanije i korporacije kojima digitalna tehnologija omogućava veću kontrolu nad tržištem kulturnih dobara posredstvom kojeg uvećevaju svoj profit.
Kao primer spomenućemo početak 1980-ih godina koji je obeležila ekspanzija širenja vlasničkog softvera kao rezultat konkurencije među proizvođačima softvera. Pokret za slobodni softver Ričarda Stalmana upravo je i formiran kao reakcija na privatizovanje softvera. Stalman je smatrao da prava, kada je u pitanju slobodan softver, treba da budu ustupljena celokupnoj zajednici, a ne da odgovaraju intresima pojedinaca i njihovom profitu.

Da li kompjuterski softver treba da bude zaštićen autorskim pravom? Ovo pitanje često je postavljano kao deo šire rasprave u vezi sa adekvatnom pravnom zaštitom digitalnih dobara. Veliki broj tradicionalnih književnih dela poput knjiga i filmova sve više se nalazi u digitalnom domenu. Autori velikog broja takvih dela žele da njihova dela budu dostupna javnosti, uz sprečavanje treće strane da onemogući dalje deljenje dela.

Da li u savremenom svetu ima smisla zaštita autorskog prava digitalnih dela? Zapravo, da li ima smisla primena autorskog prava na digitalna dela? Uzimajući u obzir činjenicu da su moderne tehnologije omogućile masovnost i dostupnost tuđeg rada, možemo reći da razvoj kopilefta i kopileft pokreta prati razvoj digitalnog okruženja. Dakle, kopileft ima mnogo veći značaj i uticaj u eri digitalne tehnologije nego što ima autorsko pravo.

\section{POJAM COPYLEFTA}

Pružanje prava ljudima da slobodno dele i raspodeljuju dela drugih ljudi, kao i da ista dela slobodno menjaju, naziva se kopileft. Termin kopileft prvi put je upotrebljen u mesečnom izdanju časopisa o kompjuterskom programiranju „Dr. Dobb’s Journal” 1976. godine [3]. Najjednostavnije rečeno, kopileft podrazumeva pravo drugog da promeni nečiji rad, odnosno legalno obezbeđeno pravo da se određeno delo može slobodno distribuirati ili preraditi. Važno je naglasiti da je kopileft (copyleft) oblik licenciranja i da se prvobitno odnosio samo na računarski softver, da bi kasnije njegova primena bila proširena i na tekstualne dokumente, slike, pesme i drugo.

Kopileft je opšti metod za besplatnu izradu radova ili programa, zahtevajući da sve prerađene ili proširene verzije programa budu takođe besplatne. Najjednostavniji način da se određeni program tj. softver učini slobodnim jeste da se stavi u javni domen pokriven autorskim pravom. Ovo omogućava ljudima da dele program i da ga dalje unapređuju ukoliko žele. Međutim, stavljanje programa u javni domen omogućava i pretvaranje programa tj. softvera u vlasnički softver. U tom slučaju ljudi koji prime ovaj program u svom izmenjenom obliku, nemaju pravo da ga modifikuju. Kako bi se korisnicima 
softvera omogućila sloboda u redistribuiranju i menjanju softvera, nastao je kopileft metod.

Kopileft pruža posebnu podršku programerima koji žele da doprinesu unapređenju i poboljšanju slobodnog softvera. Ima dosta primera gde programeri svojim izmenama na softveru žele da doprinesu celokupnoj zajednici, ali njihovi poslodavci će, s druge strane, možda poželeti da izmene na softveru pretvore u vlasnički softverski proizvod što sputava programere u njihovom doprinosu zajednici.

Programeri vlasničkih softvera koriste autorsko pravo da oduzmu slobodu korisnicima. $S$ druge strane, kopileft pokreti koriste metod autorskog prava za zaštitu softvera, ali u druge svrhe. „Programeri vlasničkih softvera koriste autorsko pravo da oduzmu slobodu korisnicima računara; mi koristimo autorsko pravo da im garantujemo njihovu slobodu... To je jedini razlog zašto smo preokrenuli ime, menjajući 'autorsko pravo' u 'kopileft'. Dakle, kopileft ne znači napuštanje autorskog prava, jer bi u suprotnom to učinilo kopileft nemogućim. Pojam 'left' kod 'copyleft-a' ne odnosi se na odsustvo ili napuštanje nečega, već označava pravac suprotan od „right” [3].

\section{COPYLEFT LICENCE}

Prvu kopileft licencu - Emaks opštu javnu licencu (Emacs General Public License) Stalman je počeo da razvija septembra 1984. godine. Međutim, veoma brzo ova licenca se pokazala nekorisnom. Godine 1985. Stalman osniva Fondaciju za slobodan softver čiji je prvi projekat bio razvoj $\mathrm{GNU}^{1}$ operativnog sistema, potpuno slobodnog kompjuterskog operativnog sistema. Osnovni cilj Fondacije bio je stvaranje slobodnog operativnog sistema sličnog Juniksu (Unix).

Fondaciju za slobodan softver Ričard Stalman je osnovao 4. oktobra 1985. godine, sa ciljem da podrži pokret slobodnog softvera koji promoviše univerzalnu slobodu studiranja, distribuiranja, kreiranja i prerade računarskog softvera. FSF (Free Software Foundation) je neprofitna organizacija sa globalnom misijom da promoviše slobodu računarskih korisnika, kao i da brani prava svih korisnika slobodnog softvera.

1 GNU je operativni sistem sastavljen isključivo od slobodnog softvera. Njegov naziv je rekurzivna skraćenica za „GNU nije juniks” (GNU's Not Unix). Ovaj naziv je odobren zato što je njegov dizajn juniksolik, ali od Juniksa se razlikuje zato što je slobodan softver i što ne sadrži njegov kod.

\section{Licence Fondacije za slobodan softver}

Fondacija za slobodan softver najzaslužnija je za prilično rasprostranjeno korišćenje Opšte javne licence slobodnog softvera (GNU General Public License - GNU GPL). Cilj primene osnovnih sloboda (prava korisnika da koriste, umnožavaju, distribuiraju, studiraju, promene i unaprede softver) korisnicima je neophodan potpuni pristup kodu.

Pored licence GNU, GPL Fondacija je objavila i licence kao što su Leser opšta javna licenca (GNU Lesser General Public License - GNU LGPL), Afero opšta javna licenca (GNU Affero General Public License - GNU AGPL) i GNU licenca za slobodnu dokumentaciju (Free Document License - GNU FDL).

Opšta javna licenca skraćeno se naziva GNU GPL i koristi se od strane većine GNU programa i više od polovine svih slobodnih softverskih paketa. Reč je o široko korišćenoj licenci slobodnog softvera, koja garantuje korisnicima slobodu u korišćenju, umnožavanju, distribuiranju, studiranju i unapređivanju softvera. „GPL je najvažnija licenca, jer ona u potpunosti ispunjava sve slobode za koje se pokret slobodnog softvera zalaže, a to je da je softver koji je pod ovom licencom dostupan svima kao slobodan softver, tako da se može dalje slobodno umnožavati i menjati”. Jedino ograničenje GPL licence je da promenjene verzije softvera koji je pod GPL licencom, ako se izdaju, moraju biti izdate pod istim uslovima pod kojim su dobijene.

GNU LGPL je licenca izdata od strane Fondacije za slobodan softver i namenjena je softverskim bibliotekama. Softverska biblioteka predstavlja kolekciju nepromenljivih resursa koje koriste programski jezici i sadrži podatke za podešavanje, dokumentaciju, pomoćne podatke, stare kodove, potprograme i drugo.

Afero opšta javna licenca je kopileft licenca za slobodni softver i druge vrste poslova, specijalno dizajnirana da bolje štiti usluge putem računarske mreže, posebno kada je reč o veb aplikacijama [4]. Dakle, licenca je dizajnirana sa ciljem da obezbedi da promenjen izvorni kod postane dostupan široj zajednici. To zahteva od operatera mrežnog servera da obezbedi da izvorni kod promenjene verzije može biti pokrenut od strane korisnika tog servera. To znači da javna upotreba promenjene verzije, na javno dostupnom serveru, daje javni pristup izvornom kodu izmenjene verzije.

Licenca za slobodnu dokumentaciju takođe je kopileft licenca koja ima za cilj da knjige, priručnike i druga dokumenta učini slobodnim u smislu da osigura svakome slobodu da ih umnožava, deli, sa ili bez menjanja sadržaja. 
Ali, sva ta dokumenta moraju sadržati imena autora, kako originalni tvorci te dokumentacije ne bi ostali bez priznanja za svoj rad.

\section{Licence Organizacije otvorenog koda}

Licence otvorenog koda su licence koje su u skladu sa definicijom otvorenog koda. Da bi određena licenca bila odobrena od strane Organizacije otvorenog koda, licenca mora da prođe kroz proces pregleda novih licenci kako bi se utvrdilo da li ona poštuje sva pravila otvorenog koda tj. da bi se utvrdilo da li postoji ista ili slična licenca. Većina kopileft licenci su licence otvorenog koda. Međutim, nisu sve licence otvorenog koda kopileft. Ukoliko određena licenca otvorenog koda nije kopileft, to znači da softver objavljen pod tom licencom može da se koristi kao deo programa distribuiranih pod drugim licencama, uključujući i vlasničke licence [5]. Kao primer licence otvorenog koda koja nije kopileft licenca spomenućemo BSD (BSD) licencu. Licence poput ove često se nazivaju „nerestriktivne” ili permissive licence otvorenog koda.

Od popularnih licenci odobrenih od strane Organizacije otvorenog koda spomenućemo Apači (Apache) licencu; Mozila licencu (Mozilla Public License); MIT licencu (Massachusetts Institute of Technology) i BSD (The Berkeley Systems Distribution - BSD) licencu.

\section{Kopileft licence otvorenog koda}

Među kopileft licencama otvorenog koda spomenućemo Mozila licencu (Mozilla Public License - MPL) koja se razvija i održava od strane Mozila fondacije. Trenutno je na snazi druga verzija licence (MPL 2.0) koja je objavljena 2012. godine. Kao što smo videli, reč je o slaboj kopileft licenci.

Mozila licenca dizajnirana je tako da je smeštena između ekstremnih oblika restriktivnih licenci kao što je GNU GPL kopileft licenca, s jedne strane, i liberalnih licenci (nerestriktivnih) poput BSD i MIT licenci [9]. Mozila licenca dozvoljava radovima koji proizilaze iz ove licence da budu objavljeni pod drugom licencom, ali još uvek zahteva formu kopilefta na nivou izvornog koda. U praksi to znači da postoji mogućnost uzimanja MPL koda i njegovog korišćenja u vlasničkom softveru, ali promenjeni delovi pokriveni MPL kodom moraju biti objavljeni pod MPL licencom. Dakle, izvorni kod mora biti licenciran pod Mozila licencom. Mozila licenca omogućava korisnicima da rade izmene na izvornom kodu, ali isto tako dopušta da se izvorni kod može kombinovati sa kodom koji je pod drugim licencama, bez obzira na to da li je softver slobodan ili ne. Mozila licenca omogućava da pokriveni izvorni kod bude mešan sa drugim kodovima koji se nalaze pod drugim licencama, čak i vlasničkom licencom. Kod licenciran pod Mozila licencom mora ostati pod tom licencom i biti dostupan u svom izvornom obliku. Specifičnost Mozila licence je da se primenjuje za svaku datoteku posebno i to što je kompatibilna sa GPL i Apači licencom [10].

\section{CREATIVE COMMONS LICENCE}

Creative Commons licence su licence koje pomažu autorima i drugum nosiocima tih prava da zadrže autorsko pravo, ali da istovremeno dozvole umnožavanje i distribuciju svojih dela. Dakle, reč je o licencama autorskog prava (copyright licenses) koje omogućavaju besplatnu distribuciju dela inače zaštićenog autorskim pravom. „CC licence koriste se onda kada autor želi da daje pravo ljudima da dele, koriste i dorađuju rad koji su stvorili... CC licence daju fleksibilnost autoru i štite ljude koji koriste ili redistribuiraju autorov rad od povrede autorskog prava dokle god se pridržavaju uslova koji su tačno navedeni u licenci”.

Creative Commons licence objavljene su decembra 2002. godine od strane organizacije Creative Commons, čiji je osnivač Lawrence Lessig. U svom radu pod nazivom "Code and Other Laws of Cyberspace" 1999. godine, Lesing je razmatrao softver otvorenog koda i izazove sa kojima se susreće internet. Lesing je ovde stavio akcenat na vezu između koda (Code) i zakona (Law) navodeći da je na internetu kod zakon (Code is Law).

\section{Creative Commons organizacija}

Creative Commons je međunarodna neprofitna organizacija osnovana 2001. godine uz podršku Centra za javni domen (Center for the Public Domain) i Vilijam i Flora Hevlet Fondacije (William and Flora Hewlett Foundation) sa ciljem da pruži jasnu predstavu o tome šta ljudi mogu da čine sa objavljenim sadržajem. Ovde se prvenstveno misli na akademske knjige i članke u naučnim časopisima, s tim što je važno spomenuti da se ove licence koriste i za ostale vrste sadržaja poput fotografija i muzičkih numera. Važno je naglasiti da CC licence nisu alternativa autorskom pravu, već da one deluju zajedno sa njim, omogućavajući zaintresovanim licima da menjaju uslove autorskog prava prema svojim potrebama. 


\section{Osnovne CC licence}

Najliberalnija CC licenca nosi naziv „Autorstvo” (Attribution - CC BY) i ona dozvoljava distribuciju, remiks, preradu, čak i u komercijalne svrhe, dela pod uslovom da se pravilno naznači ime autora. Ovo je najfleksibilnija licenca koja se upotrebljava kako bi se dozvolilo korišćenje dela.

Sledeća CC licenca slična prethodnoj jeste licenca pod nazivom „Autorstvo - deliti pod istim uslovima” (Attribution - ShareAlike - CC BY-SA). Ova licenca, kao i prethodna, dozvoljava remiks i preradu sve dok se pravilno naznači ime autora, ali i ako se prerada licencira pod istim uslovima. Dakle, svi novi radovi tj. dela koja su proizašla iz rada koji je pod ovom licencom moraju takođe biti licencirana pod istom licencom. Zbog ovoga licenca CC BY-SA često se upoređuje sa kopileft licenciranjem slobodnog softvera ili softvera otvorenog koda. Najpoznatiji korisnik ove licence je Vikipedija.

Licenca „Autorstvo - bez prerada” (Attribution NoDerivs - CC BY-ND) dozvoljava preraspodelu dela, komercijalnu i nekomercijalnu, ukoliko se pravilno naznačava ime autora i ako se delo uopšte ne menja.

"Nekomercijalno autorstvo" (Attribution -NonCommercial - CC BY-NC) kao licenca zabranjuje remiks, preradu, ili korišćenje dela u komericijalne svrhe. Iako novi radovi (prerade) moraju takođe biti nekomercijalni, oni ne moraju biti licencirani pod istim uslovima kao originalno delo.

Licenca „Autorstvo - Nekomercijalno - Deliti pod istim uslovima" (Attribution - NonCommercial - ShareAlike - CC BY-NC-SA) dozvoljava remiks i prerade glavnog dela, kao i nekomercijalno korišćenje dela, sve dok se pravilno naznači ime autora i ukoliko se prerada dela licencira pod identičnim uslovima.

Najstroža od svih šest CC licenci je licenca „Autorstvo - Nekomercijalno - Bez prerada" (Attribution - NonCommercial - NoDerivs - CC BY-NC-ND). Ova licenca dozvoljava drugima da samo preuzimaju rad i da ga dele sa drugima sve dok pravilno stoji ime autora, ali bez prava na promenu dela i prava na komercijalno korišćenje dela.

Suština CC licenci jeste u pružanju mogućnosti autoru, kao kreatoru sadržaja, da precizira kako drugi mogu i ne mogu da koriste njegov rad. Dakle, CC licence dovoljno su fleksibilne da tačno odrede šta jeste, a šta nije dozvoljeno. Nakon izbora jedne od šest CC licenci nije dozvoljeno menjanje njihove sadržine. Važno je spomenuti još jednom da CC licence nisu alternativa autorskim pravima (copyright) već da su one izgrađene na njima i da traju isto koliko autorska prava u određenom radu.

Pored šest osnovnih licenci, Creative Commons organizacija razvila je još dve alatke koje se pretežno odnose na javni domen. Reč je o mehanizmu CCO (No Rights Reserved) i Naznaci javnog domena (Public Domain Mark - No Known Copyright).

\section{CCO (No Rights Reserved)}

Mehanizam CCO omogućava naučnicima, umetnicima i drugim stvaraocima da se odreknu svih prava koja imaju nad svojim radom i u potpunosti ih stave u javni domen tako da ih i drugi mogu nadograđivati i upotrebljavati u različite svrhe bez bojazni od kršenja autorskih prava. Dakle, za razliku od CC licenci koje omogućavaju nosiocima autorskog prava da biraju između različitih licenci koje zadržavaju njihova autorska prava, mehanizam CCO im pruža jedan novi izbor - da odustanu od autorskog prava i zaštite baze podataka.

Naznaka javnog domena (Public Domain Mark - No Known Copyright)

Naznaka javnog domena omogućava radovima koji više nisu ograničeni autorskim pravom da budu označeni na jedinstven način i samim tim budu lako vidljivi i dostupni drugim ljudima. Naznaka javnog domena funkcioniše kao oznaka ili etiketa, omogućavajući institucijama kao što su muzeji i biblioteke da određene radove predstave kao radove koji više nisu ograničeni zakonom o autorskim pravima i da samim tim mogu slobodno biti korišećni. Kulturne institucije kao što su biblioteke i muzeji sadrže veliki broj radova poput knjiga, slika, fotografija, rukopisa, od kojih veliki broj njih zbog starosti više nije zaštićen autorskim pravom i samim tim sadrže oznaku javnog domena. Naznaka javnog domena ne preporučuje se za radove koji su u javnom domenu u određenim pravnim sistemima, ukoliko se zna da su isti ograničeni autoriskim pravom u drugim sistemima.

\section{Budućnost CC licenci u digitalnom okruženju}

Kada su CC licence nastale početkom 21 . veka, bilo je evidentno da digitalne tehnologije nude velike mogućnosti svakoj individui u stvaranju i širenju kreativnog rada. Prvobitno, CC licence bile su formulisane prema američkom zakonu o autorskim pravima, da bi vremenom one bile prihvaćene od strane velikog broja stvaralaca širom sveta, ali i drugih zakonodavstava. Globalno intresovanje 
za CC licence izazvalo je raspravu o potrebi formiranja nacionalnih verzija CC licenci.

Zahvaljujući modernim tehnologijama, na prvom mestu internetu, CC licence su postale poznate i priznate širom sveta. Njihov razvoj u svetu koji karakteriše veliki tehnološki progres počiva na pet strateških prioriteta:

1. Nadzor nad Global Commons;

2. Razvoj inovativnih proizvoda;

3. Jačanje partnerskih mreža;

4. Povećanje korišćenja;

5. Osigurati održivost.

Kada je reč o prvom strateškom prioritetu, organizacija CC će ostati glavni upravitelj nad CC licencama. Kao glavni nadzornik, CC mora da obezbedi da internet ostane mesto deljenja, inovacija i saradnje na globalnom nivou.

Zahvaljujući modernim tehnologijama, CC licence omogućavaju ljudima da dele svoje radove i resurse učenja, kao i da koriste i remiksuju radove drugih ljudi. Stoga je od ključnog značaja za CC da drži korak sa tehnološkim inovacijama i daljim napretkom nauke. Među inovativnim proizvodima koje CC namerava da proizvede jeste izrada interaktivnog okvira koji bi pokazao korisnicima CC licenci kako se njihov rad upotrebljava od strane drugih ljudi.

Treći strateški prioritet jeste jačanje partnerske mreže koja obuhvata više od 70 partnerskih grupa širom sveta; mnogo neformalnih grupa i volontera. Partnerska mreža promoviše CC licence na više načina, među kojima je pravna ekspertiza i edukacija javnosti o licenciranju.

CC licence omogućile su novim poslovima da napreduju u digitalnom okruženju i da budu ugrađene u neke od najvećih platformi na internetu. Ove platforme omogućavaju domet ka različitim zajednicama na globalnoj mreži, ali i pomažu izgradnji svesti o otvorenim licencama.

Obezbeđivanje održivosti predstavlja peti strateški prioritet. U periodu 2013-2015. godine, CC je radio na sledećim osnovnim elementima održivosti: obezbediti sredstva za osnovne potrebe; razviti model dugoročnog prihoda i obezbediti jaku organizacionu strukturu.

\section{ZAKLJUČAK}

"Autorsko pravo je monopol i proizvodi sve one efekte koje opšti glas čovečanstva pripisuje monopolu... efekat monopola je da učini članke retkim, da ih načini skupim... Dobro je što autori treba da budu nagrađeni... Ipak, monopol je zlo. Radi dobra mi moramo potčiniti to zlo; ali to zlo ne bi trebalo da traje ni dan duže nego što je neophodno u cilju obezbeđivanja dobra" [1]. Ovo su reči britanskog parlamentarca Tomasa Babingtona Macaulaia (Thomas Babington Macaulay) iz 1841. godine. Čini se da nikad kao danas u eri digitalne tehnologije ove reči ne poprimaju toliki značaj. Autorsko pravo štiti kreatore dela i vidi ljude kao mušterije, dok kopileft u ljudima pre svega vidi autore.

Koreni borbe za slobodan softver i nastanak prvih kopileft pokreta nalaze se u osnovnim ljudskim pravima među kojima je i pravo na slobodan i otvoren pristup znanju. Kao što smo videli, reč je o pravima koja su zagarantovana Deklaracijom o ljudskim pravima. Sa napretkom nauke i tehnologije u 20. veku došlo je do masovne proizvodnje intelektulanih tvorevina i njihovog korišćenja. Zbog toga se na autorsko pravo gledalo, i još uvek se gleda, kao na vid zaštite intelektualnih dela. Reč je o pravima koja uživaju iskuljučivo stvaraoci intelektualnih dela, a koja im daju pravo korišćenja ili odobravanja drugima korišćenja svog dela.

Kopileft ne predstavlja negaciju autorskog prava, već specifičnost kopilefta jeste u tome što se tvorac softvera, koji želi svoje delo da učini slobodnim, ne odriče zakonom priznatog autorskog prava, već ga koristi tako što svoja imovinskopravna ovlašćenja ustupa svim zaintresovanim licima, pod uslovom da ista sloboda prati svaki dalji prerađen ili neprerađen softver. Dakle, suština kopilefta i ideje slobodnog softvera jeste u slobodi prerade, umonožavanja i vršenja drugih izmena na softveru pod uslovom da lice koje vrši dalje izmene na softveru ima ista prava i ne sme da postavlja ograničenja drugima koje ni sam nije imao.

Šta motiviše ljude da objave svoje delo pod kopileft licencom? U strogo poslovnom okruženju i tamo gde je profit primaran može biti zapanjujuć pokušaj da se razume šta je to što određene autore motiviše da svoje delo stave pod kopileft zaštitu. Takođe, nije mali broj onih koji predviđaju ne baš svetlu budućnost kopileft pokreta. „Ima onih koji tvrde da će bez validne komercijalne aplikacije kopilef pokret sigurno propasti”. Međutim, sve veća dostupnost dela koja su pod kopileft licencom jasno ukazuju da pokret ne gubi zamah. Takođe, prednosti koje kopileft pruža mnogo su veće od njegovih nedostataka. Prednosti koje kopileft ima u informacionom društvu na prvom mestu je činjenica da je kopileft softver besplatan i da ima niže naknade savetovanja u poređenju sa vlasničkim softverom. Zatim, s obzirom na to da je kopileft softver dostupan, softver pod autorskim pravom mora da se takmiči u ceni i efikasnosti. Kada je reč o nedostacima kopilefta, tu ćemo navesti: kompleksnost 
kopileft zakona koji odvraćaju mnoge da koriste kopileft softver; originalni autor proizvoda može imati sukob sa budućim korisnicima originalnog proizvoda.

Kopileft licence i njihova zaštita slobodnog pristupa javnom interesu nastaviće da igraju važnu ulogu u razvoju prava intelektualne svojine. Kopileft ne podrazumeva samo zaštitu prava na intelektualnu svojinu, već i zaštitu prava zajednice da koristi intelektualnu svojinu u cilju razvoja i dobrobiti zajednice.

Kakva je budućnost autorskog prava? Postoje tri moguća scenarija kada je u pitanju budućnost autorskog prava. Prema prvom scenariju autorsko pravo prevladaće digitalnu kulturu, a kombinacija pojačanih zakona o autorskom pravu i međunarodnih sporazuma konačno će omogućiti industriji autorskog prava da uspostavi kontrolu nad digitalnim sadržajem i samim tim uguši digitalnu kulturu; prema drugom scenariju digitalna kultura će se uspešno smestiti unutar postojećeg okvira autorskog prava; prema trećem digitalna kultura neće biti sadržana u starom režimu autorskog prava i samim tim će dovesti do promena u autorskom pravu.

Pored kopilefta, sa jedne, i autorskog prava, sa druge strane, da li možemo govoriti o novom, trećem načinu proizvodnje i distribucije digitalnih radova, odnosno da li se može pronaći novi način upravljanja intelektualnom svojinom u skladu sa razvojem digitalnog okruženja? S obzirom na to da živimo u eri digitalne tehnologije i da se povećava broj radova u digitalnom okruženju, neophodno je uzeti u obzir mogućnost formiranja trećeg puta - između autorskog prava i kopilefta.

Vilijam Fišer (William Fisher) razmatrao je tri alternativne mogućnosti promena u sistemu upravljanja intelektualnom svojinom. „Prvi predstavlja sistem prinudne naplate koji bi počivao na registraciji radova i dodeli jedinstvenog digitalnog imena datoteke; druga opcija je zasnovana na priznanju da je autorsko pravo pravo svojine koje treba sagledavati iz ugla zakona; treća mogućnost je da se na industriju zabave gleda kao na javno dobro $i$ uvođenje zakona sličnih onima koji regulišu industrije kao što su telefonske kompanije".

Razvoj i napredovanje digitalnih tehnologija nemoguće je zaustaviti i upravo iz tog razloga kopileft pokreti $i$ kopileft licence imaju sve veći značaj. Međutim, uprkos jačanju kopilefta ne možemo govoriti o nestanku autorskog prava u budućnosti. Svaki pojedinac treba da ima slobodu u određivanju da li će svoj rad zaštiti autorskim pravom (copyright-protected) ili će ga osloboditi autorskog prava (copyright-free). Nemogućnost biranja jedne od dve opcije značila bi kršenje ljudskih prava - prava slobodnog korišćenja ili odobravanja drugim korišćenja svoga dela.
Razvoj kopilefta prati razvoj modernih tehnologija i prilagođava se njihovom razvoju. Ideja kopilefta i zalaganja za slobodni softver imaju veliku važnost u eri moderne tehnologije. S obzirom na prilično masovnu proizvodnju softvera, od velike je važnosti postojanje slobode da se određeno delo može dalje menjati i nadograđivati bez bojazni od kršenja autorskog prava. Postojanje kopileft licenci ima veliki značaj za napredak modernih tehnologija jer omogućava pojedincima da slobodno ispolje svoju kreativnost i tako doprinesu razvoju društva. Možemo zaključiti da će ideja kopilefta i zalaganje za slobodni softver imati važnu ulogu u razvoju modernih tehnologija, posebno interneta, kao i u razvoju prava intelektualne svojine u budućnosti. Izazovi kopileft pokreta u budućnosti su veliki, ali oni neće dovesti u pitanje opstanak i funkcionisanje samog pokreta i njihovih najvažnijih načela.

\section{LITERATURA}

[1] D. M. Berry, Copy, Rip, Burn, The Politics of Copyleft and Open Source, Pluto Press, 2008, 160str.

[2] A. Uzelac, Digitalna kulturna dobra u informacijskom društvu između javnog domena i privatnog vlasništva, Institut za međunarodne odnose, 2004, 46., http://hrcak.srce.hr/file/36250;

[3] D. A. Frantsvog, J.D., All Rights Reversed: A Study Of Copyleft, Open-Source, And Open-Content Licensing, Contemporary Issues In Education Research, Volume 5, Number 1, 2012, 16., http://files. eric.ed.gov/fulltext/EJ1073128.

[4] What is Copyleft? https://www.gnu.org/copyleft/ copyleft.html

[5] GNU je operativni sistem sastavljen isključivo od slobodnog softvera. Njegov naziv je rekurzivna skraćenica za „GNU nije juniks“ (GNU's Not Unix). Ovaj naziv je odobren zato što je njegov dizajn juniksolik, ali od Juniksa se razlikuje zato što je slobodan softver i što ne sadrži njegov kod.

[6] GNU Affero General Public License - AGPL, https://www.gnu.org/licenses/agpl-3.0.html

[7] GNU Affero General Public License - AGPL, https://www.gnu.org/licenses/agpl-3.0.html

[8] What is "copyleft"? Is it the same as "open source"? https://opensource.org/faq\#free-software

[9] The Mozilla Public License Version 2.0: A Good Middle Ground?, https://julien.ponge.org/blog/ mozilla-public-license-v2-a-good-middleground/<

[10] C. Mario, Filozofija slobodnog softvera, Fakultet organizacije i informatike, Varaždin, 2012

[11] S. Radovanovic, Ugovor o licenci softvera, Pravni fakultet Univerziteta u Beogradu, str.39 


\title{
COPYLEFT LICENSES AND THE DEVELOPMENT OF INTELLECTUAL PROPERTY RIGHTS
}

\begin{abstract}
:
The emergence of the Internet has greatly changed the usage of copyright works. Bearing in mind that a large number of works are widely available and distributed on the Internet, the term of copyright is increasingly being disputed, and an increasing number of works is being protected by copyleft licenses. Main principle of copyleft is the right to free access to knowledge, namely the right of everybody to freely use, rearrange and distribute certain work. The concept of copyleft is a relatively recent concept that requires a more detailed analysis, especially considering the fact that the small number of people in our region is familiar with it. The main objective of our research is to introduce the concept of copyleft, copyleft movement and the copyleft license, as well as the impact of the digital environment on their development.
\end{abstract}

Keywords:

Internet, copyright, copyleft, license, movement. 